\title{
Remote ischaemic preconditioning influences the levels of acylcarnitines in vascular surgery: a randomised clinical trial
}

\author{
Teele Kasepalu ${ }^{1,2^{*}}$ (D) Karl Kuusik ${ }^{2,3}$, Urmas Lepner ${ }^{1,4}$, Joel Starkopf ${ }^{4,5}$, Mihkel Zilmer ${ }^{2}$, Jaan Eha ${ }^{3,4}$, Mare Vähi ${ }^{6}$
} and Jaak Kals ${ }^{1,2,4}$

\begin{abstract}
Background: Vascular surgery patients have reduced tissues` blood supply, which may lead to mitochondrial dysfunction and accumulation of acylcarnitines (ACs).It has been suggested that remote ischaemic preconditioning (RIPC) has its organ protective effect via promoting mitochondrial function. The aim of this study was to evaluate the effect of RIPC on the profile of ACs in the vascular surgery patients.
\end{abstract}

Methods: This is a randomised, sham-controlled, double-blinded, single-centre study. Patients undergoing open surgical repair of abdominal aortic aneurysm, surgical lower limb revascularisation surgery or carotid endarterectomy were recruited non-consecutively. The RIPC protocol consisting of 4 cycles of $5 \mathrm{~min}$ of ischaemia, followed by $5 \mathrm{~min}$ of reperfusion, was applied. A blood pressure cuff was used for RIPC or a sham procedure. Blood was collected preoperatively and approximately $24 \mathrm{~h}$ postoperatively. The profile of ACs was analysed using the AbsolutelDQp180 kit (Biocrates Life Sciences AG, Innsbruck, Austria).

Results: Ninety-eight patients were recruited and randomised into the study groups and 45 patients from the RIPC group and 47 patients from the sham group were included in final analysis. There was a statistically significant difference between the groups regarding the changes in $\mathrm{C} 3-\mathrm{OH}(p=0.023)$ - there was a decrease $(-0.007 \mu \mathrm{mol} / \mathrm{L}, \pm 0$. $020 \mu \mathrm{mol} / \mathrm{L}, p=0.0233)$ in the RIPC group and increase $(0.002 \mu \mathrm{mol} / \mathrm{L}, \pm 0.015 \mu \mathrm{mol} / \mathrm{L}, p=0.481)$ in the sham group. Additionally, a decrease from baseline to $24 \mathrm{~h}$ after surgery $(p<0.05)$ was detected both in the sham and the RIPC group in the levels of following ACs: C2, C8, C10, C10:1, C12, C12:1, C14:1, C14:2, C16, C16:1, C18, C18:1, C18:2. In the sham group, there was an increase $(p<0.05)$ in the levels of $\mathrm{CO}$ (carnitine) and a decrease in the level of $\mathrm{C} 18: 1-\mathrm{OH}$. In the RIPC group, a decrease $(p<0.05)$ was noted in the levels of $\mathrm{C} 3-\mathrm{OH}, \mathrm{C3}-\mathrm{DC}(\mathrm{C} 4-\mathrm{OH}), \mathrm{C6}: 1, \mathrm{C}, \mathrm{C}, \mathrm{C} 0: 2$.

Conclusions: It can be concluded that RIPC may have an effect on the levels of ACs and might therefore have protective effects on mitochondria in the vascular surgery patients. Further larger studies conducted on homogenous populations are needed to make more definite conclusions about the effect of RIPC on the metabolism of ACs.

Trial registration: ClinicalTrials.gov database, NCT02689414. Registered 24 February 2016—Retrospectively registered, https://clinicaltrials.gov/ct2/show/NCT02689414.

Keywords: Acylcarnitines, Ischaemic preconditioning, Mitochondria, Vascular surgery

*Correspondence: Teele.Kasepalu@kliinikum.ee

${ }^{1}$ Department of Surgery, Institute of Clinical Medicine, University of Tartu, Puusepa 8, 50406 Tartu, Estonia

Full list of author information is available at the end of the article

c) The Author(s) 2020. This article is licensed under a Creative Commons Attribution 4.0 International License, which permits use, sharing, adaptation, distribution and reproduction in any medium or format, as long as you give appropriate credit to the original author(s) and the source, provide a link to the Creative Commons licence, and indicate if changes were made. The images or other third party material in this article are included in the article's Creative Commons licence, unless indicated otherwise in a credit line to the material. If material is not included in the article's Creative Commons licence and your intended use is not permitted by statutory regulation or exceeds the permitted use, you will need to obtain permission directly from the copyright holder. To view a copy of this licence, visit http://creativeco mmons.org/licenses/by/4.0/. The Creative Commons Public Domain Dedication waiver (http://creativecommons.org/publicdomain/ zero/1.0/) applies to the data made available in this article, unless otherwise stated in a credit line to the data. 


\section{Background}

Remote ischaemic preconditioning (RIPC) is an experimental procedure in which short episodes of ischaemia are induced in order to offer organ protection to distant tissues. We along other investigators have demonstrated that RIPC has protective effects to heart,kidneys, brain and other organs in the case of ischaemia-reperfusion injury [1-5]. The exact mechanisms of RIPC are not known, but during the last decade multiple pathways and biochemical markers involved in achieving the effect of RIPC have been discovered. It has been found that cardioprotection by RIPC occurs along with improved mitochondrial function in animal studies $[6,7]$. As ischaemia-reperfusion injury is known to impair mitochondrial function, the effect of RIPC might be beneficial in reducing the extent of injury. Ischaemia-reperfusion injury is inevitable in vascular surgery. Also, surgery induces acute stress response, which in turn promotes catabolic pathways including fatty-acid catabolism in beta-oxidation hereby increasing the load on mitochondria even more. Mitochondria have a principal position in energy metabolism and intensification of the betaoxidation of fatty acids in mitochondria leads to elevated ATP production due to integrated action of the Krebs cycle and the respiratory chain. In the case of mitochondrial dysfunction, fatty acid $\beta$-oxidation is diminished, resulting in accumulation of acylcarnitines (ACs) $[8,9]$. ACs are esters of L-carnitine and fatty acids and due to existence of different fatty acids [10], a large set of ACs can be produced that are generally divided into short, medium and long chain ACs (denoted as SCACs, MCACs and LCACs). For transport of fatty acid into mitochondria for beta-oxidation, the coenzyme A group is attached and afterwards displaced by carnitine forming an acylcarnitine, which is able to enter the mitochondrial matrix where it can be broken down by carnitine palmitoyl transferase II to release activated fatty acid to enter beta-oxidation [11]. It is crucial to produce LCACs as mitochondrial inner membrane is impenetrable for long chain fatty acids. Because of this, the increase of LCACs is most commonly associated with metabolic disorders such as mitochondrial dysfunction and genetic enzyme deficiencies [11]. However, as more knowledge has been gained about the role of SCACs and MCACs, it is necessary to simultaneously investigate changes of SCACs, MCACs and LCACs.

Considering all this, shifts in the ACs profile might occur in response to RIPC in patients undergoing vascular surgery. To our knowledge, no studies have been published about the effect of RIPC on the whole profile (C2-C18) of ACs.
This is a substudy within our large clinical trial conducted for evaluating the effect of RIPC on arterial stiffness and end-organ damage [1, 2, 12]. Among our secondary aims was to investigate changes in the levels of ACs. We hypothesised that RIPC may prevent the increase of the levels of ACs, ensuing from metabolic shifts in patients undergoing vascular surgery and the aim of the current study was to test this hypothesis.

\section{Methods}

\section{Study groups and eligibility}

This randomised double-blinded sham-controlled clinical trial was conducted at the Department of Vascular Surgery, Clinic of Surgery, at Tartu University Hospital.

Patients undergoing open surgical repair of infra-renal abdominal aortic aneurysm (AAA) or surgical lower limb revascularisation surgery (for claudication or critical limb ischaemia; common femoral artery endarterectomy, aorto(bi)femoral or femoropopliteal or femorotibial or iliofemoral bypass surgery) or carotid endarterectomy (for symptomatic or asymptomatic carotid stenosis) during the period from January 1, 2016 to February 8, 2018 were recruited non-consecutively.

Signed informed consent was obtained from each patient.

The research protocol of our study was approved by the Research Ethics Committee of the University of Tartu, and was registered in the ClinicalTrials.gov database (NCT02689414).

The following exclusion criteria were applied: age under 18 years, pregnancy, known malignancy in the past 5 years, permanent atrial fibrillation or flutter, symptomatic upper limb atherosclerosis, need for oxygen therapy at home, estimated preoperative glomerular filtration rate $(\mathrm{eGFR})<30 \mathrm{~mL} / \mathrm{min} / 1.73 \mathrm{~m}^{2}$, myocardial infarction in the past month, previous history of upper limb vein thrombosis or vascular surgery in the axillary region, and inability to follow the study regimen.

\section{Intervention}

The RIPC protocol consisted of four 5-min episodes of ischaemia with a 5 -min period of reperfusion between the episodes, which has been one of the most often used protocols in earlier studies. Ischaemia was achieved by placing a blood pressure cuff on an arm and raising cuff pressure to $200 \mathrm{mmHg}$. In case the patient's blood pressure exceeded $180 \mathrm{mmHg}$, the cuff pressure was raised to a value that was $20 \mathrm{mmHg}$ higher than systolic blood pressure. For sham group patients, cuff pressure was kept at level of venous pressure $(10-20 \mathrm{mmHg})$. Intervention began along with preparation for anaesthesia in the operating theatre. Any other aspects of surgery, including anaesthesia and medication use, were not affected. The 
principal investigator was in charge of patient recruitment, assignment to intervention and data storage.

\section{Blinding}

The patient, surgeon, anaesthesiologist and everyone else in the surgical team were blinded to study intervention. The scale of the manometer was kept covered. The statistician was blinded to the meaning of the group affiliation.

\section{Outcomes}

Blood samples for analysis of ACs were collected in the morning of surgery and approximately $24 \mathrm{~h}$ after surgery. The last blood collection was set as close as possible to $24 \mathrm{~h}$ after surgery on condition that the patient had fasted for at least $3 \mathrm{~h}$. Blood samples were centrifuged, serum was separated and stored in the refrigerator at $-80^{\circ} \mathrm{C}$.

The levels of ACs were analysed using the AbsoluteIDQp180 kit (Biocrates Life Sciences AG, Innsbruck, Austria). The analytical procedure was performed according to the manufacturer's standard protocol in the laboratory of the Department of Biochemistry, University of Tartu. In brief, for targeted analysis of metabolites internal standard was pipetted onto a 96-well extraction plate and $10 \mu \mathrm{L}$ serum was added to each well. Drainage was achieved with nitrogen and derivatisation was performed with phenylisothiocyanate. The measurements were accomplished with QTRAP 4500 (ABSciex, USA) coupled to an Agilent 1260 series HPLC (USA), using the $\mathrm{C} 18$ column and flow injection analysis. The vendor's software with internal standards' intensities was used to calculate the concentrations of ACs along with other metabolites, which are not discussed in this paper.

Blood samples for analysis of high sensitivity troponin $\mathrm{T}$ (hs-TnT) and N-terminal pro-brain natriuretic peptide (NT-proBNP) which were used to calculate correlations, were collected along with the samples for analysis of ACs preoperatively and approximately $24 \mathrm{~h}$ after surgery. The levels of cardiac biomarkers were analysed at the United Laboratories of Tartu University Hospital.

Sandwich electrochemiluminescence immunoassays (ECLIA), specifically the Elecsys troponin T high-sensitive assay as STAT version (Roche Diagnostics) and Elecsys proBNP II (Roche Diagnostics) were used according to the manufacturer's protocol for analysis of hs-TnT and NT-proBNP.

All patients were asked about their previous and current health issues and medications; an electronic health database was also used for complete anamnesis.

\section{Statistical analysis}

Two groups were compared using Student's $t$ test or the Wilcoxon rank-sum or Chi-squared test as appropriate. Student's $t$ test was used in baseline characteristics comparison where normal distribution was present. Wilcoxon rank-sum test was used in baseline comparison where normal distribution was not present. Because of the issue of multiple comparison, Benjamini-Hochberg procedure was used to control false discovery rate. For assessing correlations between changes in the levels of $\mathrm{AC}$ and cardiac biomarkers, Spearman's correlation coefficient was employed.

$P$ values under 0.05 were considered significant. Statistical analysis was performed by a qualified statistician from the University of Tartu.

As the study's primary outcomes were parameters of arterial stiffness, calculation of sample size was based on their values [12]. For both groups, calculated sample size was 44 .

\section{Results}

Ninety-eight patients were recruited and randomised into the study groups and 45 patients from the RIPC group and 47 patients from the sham group were included in final analysis.

Detailed patient flow is depicted in Fig. 1.The median time from the end of intervention to the beginning of surgery did not differ significantly $(p=0.057)$ between the RIPC (36 min, IQR 21-46 $\mathrm{min}$ ) and the sham group (25 min, IQR 15-38 min). There were no significant differences in the baseline values of ACs (Additional file 1). The baseline characteristics (including medications, comorbidities, preoperative risk of surgery) of the two groups were similar (Table 1). No adverse events due to

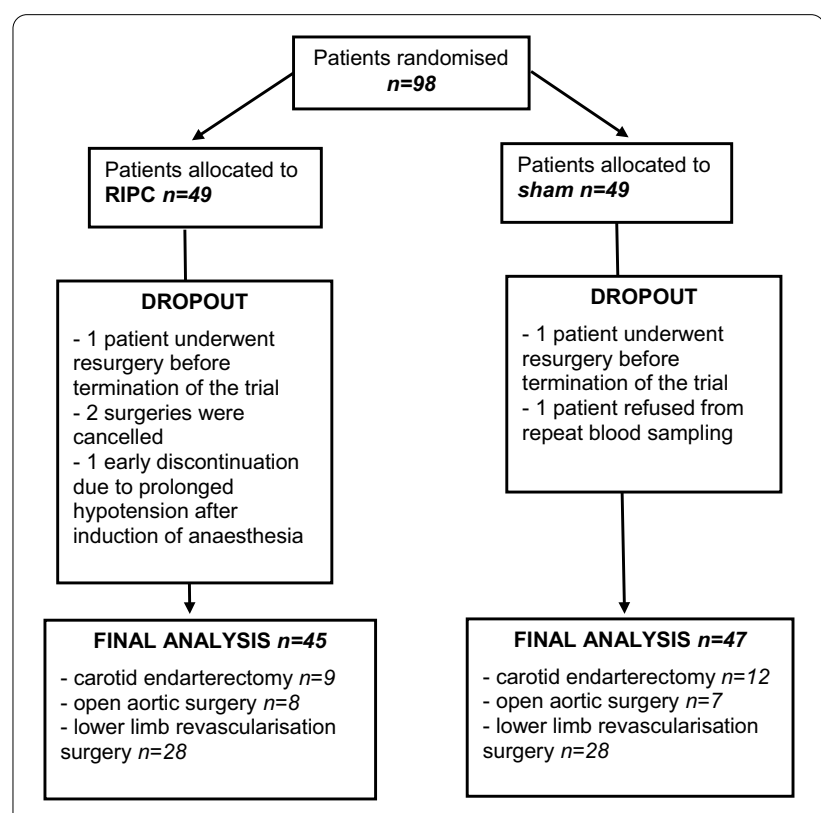

Fig. 1 Patients' flow chart 
Table 1 Baseline characteristics

\begin{tabular}{|c|c|c|c|}
\hline Variable & $\operatorname{RIPC}(n=45)$ & SHAM $(n=47)$ & $p$ value \\
\hline Age, years (SD) & $67( \pm 9)$ & $66( \pm 10)$ & 0.577 \\
\hline Male, n (\%) & $36(80)$ & $32(68)$ & 0.288 \\
\hline $\mathrm{BMI}, \mathrm{kg} / \mathrm{m}^{2}(\mathrm{SD})$ & $26.3( \pm 6.4)$ & $26.5( \pm 6.7)$ & 0.840 \\
\hline ASA 2, n (\%) & $18(40)$ & $19(40)$ & 1 \\
\hline ASA 3, n (\%) & $20(44)$ & $22(47)$ & 0.986 \\
\hline ASA $4, n(\%)$ & $7(16)$ & $6(13)$ & 0.933 \\
\hline ACEl or ARB, $n(\%)$ & $21(47)$ & $30(64)$ & 0.148 \\
\hline $\begin{array}{l}\text { Calcium channel blockers, } \\
\text { n (\%) }\end{array}$ & $9(20)$ & $17(37)$ & 0.135 \\
\hline Beta-blockers, n (\%) & $11(24)$ & $19(40)$ & 0.158 \\
\hline Statins, n (\%) & $13(29)$ & $14(30)$ & 1 \\
\hline Diabetes, n (\%) & $5(11)$ & $8(17)$ & 0.607 \\
\hline Myocardial infarction, n (\%) & $8(18)$ & $3(6)$ & 0.172 \\
\hline Stroke, n (\%) & $10(22)$ & $12(26)$ & 0.899 \\
\hline $\begin{array}{l}\text { Smoker (current or ex- } \\
\text { smoker), n (\%) }\end{array}$ & $40(89)$ & $42(89)$ & 1 \\
\hline MAP, mmHg (SD) & $99( \pm 12)$ & $100( \pm 11)$ & 0.678 \\
\hline Heart rate, bpm (SD) & $66( \pm 9)$ & $67( \pm 11)$ & 0.754 \\
\hline Cholesterol, mmol/L (IQR) & $5.0(4.2-5.7)$ & $5.0(3.9-5.6)$ & 0.793 \\
\hline $\mathrm{LDL}, \mathrm{mmol} / \mathrm{L}(\mathrm{IQR})$ & $3.4(8.1-10.4)$ & $3.3(2.5-3.8)$ & 0.500 \\
\hline $\mathrm{HDL}, \mathrm{mmol} / \mathrm{L}(\mathrm{QQR})$ & $1.1(0.9-1.4)$ & $1.1(1.0-1.3)$ & 0.311 \\
\hline Triglycerides, mmol/L (IQR) & $1.6(1.3-1.8)$ & $1.5(1.2-2.0)$ & 0.787 \\
\hline $\begin{array}{l}\text { Administration of propofol, } \\
\text { n (\%) }\end{array}$ & $19(42)$ & $26(55)$ & 0.295 \\
\hline Duration of surgery, min (IQR) & $108(89-135)$ & $112(84-156)$ & 0.827 \\
\hline
\end{tabular}

$B M I$ body mass index, ASA American Society of Anaesthesiologists' physical status score, $A C E l$ angiotensin-converting-enzyme inhibitor, $A R B$ angiotensin II receptor blocker, $P S B P$ peripheral systolic blood pressure, $P D B P$ peripheral diastolic blood pressure, CSBP central systolic blood pressure, $C D B P$ central diastolic blood pressure, MAP mean arterial blood pressure, $S D$ standard deviation, $I Q R$ interquartile range. $p$ values were calculated for data with normal distribution (presented as mean and SD) with Student's $t$ test; for data with nonnormal distribution (presented as median and IQR) with Wilcoxon rank-sum test; and for binary data (presented as number and percentage) with Chi-squared test

RIPC were described and no patient found the RIPC or the sham procedure unbearable.

\section{Changes in the levels of ACs in the RIPC and in the sham group (Table 2)}

There was a statistically significant difference between the groups regarding the changes in $\mathrm{C} 3-\mathrm{OH}(p=0.023)-$ there was a significant decrease $(-0.007 \mu \mathrm{mol} / \mathrm{L}, \pm 0.020$ $\mu \mathrm{mol} / \mathrm{L}, p=0.0233)$ in the RIPC group and insignificant increase $(0.002 \mu \mathrm{mol} / \mathrm{L}, \pm 0.015 \mu \mathrm{mol} / \mathrm{L}, p=0.481)$ in the sham group.

A statistically significant decrease $(p<0.05)$ was detected both in the sham and the RIPC group in the levels of following ACs: C2, C8, C10, C10:1, C12, C12:1, C14:1, C14:2, C16, C16:1, C18, C18:1, C18:2. In the sham group, there was a statistically significant increase $(p<0.05)$ in the levels of C0 (carnitine) and a statistically significant decrease in the level of $\mathrm{C} 18: 1-\mathrm{OH}$. In the RIPC group, a statistically significant decrease $(p<0.05)$ was noted in the levels of C3-OH, C3-DC (C4-OH), C6:1, C9, C10:2.

\section{Correlations between change in hs-TnT and changes in the levels of ACs (Table 3)}

In the RIPC group, there were statistically significant positive correlations between change of hs-TnT and change of C4 (cor $=0.38, p=0.01), \mathrm{C} 10$ (cor $=0.38, p=0.010)$, $\mathrm{C} 10: 1(\operatorname{cor}=0.38, p=0.010), \mathrm{C} 12: 1(\operatorname{cor}=0.31, p=0.037)$, $\mathrm{C} 18: 1$ (cor $=0.32, p=0.030)$ and $\mathrm{C} 18-\mathrm{OH}$ (cor $=0.35$, $p=0.019$ ). In the sham group, there was statistically significant negative correlation between change of hs-TnT and change of $\mathrm{C} 5-\mathrm{OH}$ ( $\mathrm{cor}=-0.34, p=0.021)$. No other significant correlations were observed between changes in the levels of hs-TnT and ACs in the sham group.

\section{Correlations between change in NT-proBNP and changes in the levels of ACs (Table 3)}

In the RIPC group a statistically significant positive correlation occurred between change of NT-proBNP and change of $\mathrm{C} 16: 2$ (cor $=0.34, p=0.021)$. In the sham group, a statistically significant positive correlation occurred between change of NT-proBNP and change of C18 (cor $=0.31, p=0.031$ ) and statistically significant negative correlation between change of NT-proBNP and change of $\mathrm{C} 16: 1$ (cor $=-0.35, p=0.016$ ).

\section{Discussion}

There have been no studies evaluating the effect of RIPC on the level of carnitine ( $\mathrm{C} 0$ ) and on the profile of all acylcarnitines $(\mathrm{C} 2-\mathrm{C} 18)$. In this study we describe the positive effect of RIPC in lowering the levels of several ACs in patients undergoing vascular surgery. We noted a statistically significant difference in changes in the level of $\mathrm{C} 3-\mathrm{OH}$ between the RIPC and sham groups. In addition, there was a statistically significant increase in the levels of $\mathrm{CO}$ in the sham group, no significant increase occurred in the levels of any ACs but a statistically significant decrease occurred in the levels of C3, C3-OH, C3-DC (C4-OH), C4, C5, C6:1, C9, C10:2 in the RIPC group. All these findings indicate the RIPC-directed effect on the ACs profile in plasma.

Based on previous studies, the decrease in the levels of ACs can be associated with preserved mitochondrial function [9] whereas their increase has been linked to increased mortality in chronic heart failure patients [8] and worse prognosis in patients with IgA nephropathy [13]. Several carnitine esters and members of the ACs are elevated in patients with peripheral artery disease (PAD) [14]. Nevertheless, the impact of ACs in clinical practice is unknown as relevant studies are lacking. 
Table 2 Changes in the levels of acylcarnitine esters from baseline to $24 \mathrm{~h}$ postoperatively

\begin{tabular}{|c|c|c|c|c|c|}
\hline & SHAM & & RIPC & & \\
\hline & Change ( $\mu \mathrm{mol} / \mathrm{L})$ & $p$ value & Change ( $\mu \mathrm{mol} / \mathrm{L})$ & $p$ value & value \\
\hline $\mathrm{CO}$ & $2.900(-2.700$ to 7.200$)$ & 0.0173 & $1.600(-2.500$ to 7.200$)$ & 0.0628 & 0.7057 \\
\hline C2 & $-0.850(-2.300$ to 0.230$)$ & 0.0149 & $-1.300(-2.710$ to 0.270$)$ & 0.0051 & 0.7912 \\
\hline C3 & $-0.009(-0.152$ to 0.160$)$ & $<0.0001$ & $-0.077(-0.250$ to 0.083$)$ & $<0.0001$ & 0.2428 \\
\hline C3-DC & $-0.003(-0.018$ to 0.010$)$ & 0.3944 & -0.004 ( -0.017 to 0.008$)$ & 0.0488 & 0.7231 \\
\hline $\mathrm{C} 3-\mathrm{OH}$ & 0.002 ( -0.010 to 0.011$)$ & 0.4809 & $-0.005(-0.018$ to 0.007$)$ & 0.0233 & 0.0232 \\
\hline C3:1 & $-0.002(-0.012$ to 0.008$)$ & 0.9557 & $-0.001(-0.014$ to 0.008$)$ & 0.4578 & 0.6078 \\
\hline C4 & $0.008(-0.043$ to 0.078$)$ & $<0.0001$ & $-0.020(-0.075$ to 0.042$)$ & $<0.0001$ & 0.2042 \\
\hline$C 4: 1$ & $0.002(-0.007$ to 0.011$)$ & 0.2679 & $-0.003(-0.014$ to 0.011$)$ & 0.2227 & 0.0976 \\
\hline C5 & $-0.005(-0.036$ to 0.061$)$ & $<0.0001$ & $-0.045(-0.107$ to 0.045$)$ & $<0.0001$ & 0.0553 \\
\hline C5-DC (C6-OH) & $0.003(-0.014$ to 0.013$)$ & 0.8467 & $0.000(-0.010$ to 0.017$)$ & 0.4274 & 0.7236 \\
\hline C5-M-DC & $0.008(-0.005$ to 0.026$)$ & 0.0504 & $0.005(-0.007$ to 0.015$)$ & 0.1865 & 0.3989 \\
\hline $\mathrm{C} 5-\mathrm{OH}(\mathrm{C} 3-\mathrm{DC}-\mathrm{M})$ & $0.002(-0.013$ to 0.006$)$ & 0.4681 & $-0.003(-0.011$ to 0.005$)$ & 0.3501 & 0.6769 \\
\hline C5:1 & $0.000(-0.008$ to 0.010$)$ & 0.7822 & -0.007 ( -0.017 to 0.006$)$ & 0.2437 & 0.0583 \\
\hline C5:1-DC & 0.003 (- 0.007 to 0.011$)$ & 0.0931 & $-0.001(-0.006$ to 0.007$)$ & 0.5304 & 0.1824 \\
\hline C6 (C4:1-DC) & $-0.001(-0.004$ to 0.001$)$ & 0.2417 & $-0.001(-0.004$ to 0.001$)$ & 0.2027 & 0.7639 \\
\hline C6:1 & 0.000 (- 0.001 to 0.001$)$ & 0.8706 & $-0.001(-0.001$ to 0.001$)$ & 0.0482 & 0.1071 \\
\hline C7-DC & $-0.003(-0.011$ to 0.007$)$ & 0.1833 & -0.001 ( -0.010 to 0.007$)$ & 0.2147 & 0.9025 \\
\hline $\mathrm{C} 8$ & $-0.026(-0.062$ to $(-0.001))$ & 0.0017 & $-0.035(-0.059$ to 0.002$)$ & 0.0002 & 0.9658 \\
\hline C9 & $-0.001(-0.014$ to 0.016$)$ & 0.8637 & $-0.005(-0.020$ to 0.006$)$ & 0.0230 & 0.0590 \\
\hline $\mathrm{C} 10$ & $-0.097(-0.150$ to $(-0.015))$ & $<0.0001$ & $-0.078(-0.0198$ to $(-0.012))$ & $<0.0001$ & 0.9348 \\
\hline C10:1 & $-0.022(-0.53$ to 0.002$)$ & 0.0005 & $-0.021(-0.062$ to 0.001$)$ & $<0.0001$ & 0.6856 \\
\hline $\mathrm{C} 10: 2$ & $-0.002(-0.019$ to 0.014$)$ & 0.4419 & $-0.010(-0.021$ to 0.002$)$ & 0.0074 & 0.1454 \\
\hline C12 & $-0.015(-0.047$ to 0.005$)$ & $<0.0001$ & $-0.017(-0.045$ to 0.006$)$ & $<0.0001$ & 0.8395 \\
\hline C12-DC & $-0.007(-0.024$ to 0.005$)$ & 0.0699 & 0.001 ( -0.010 to 0.019 ) & 0.9137 & 0.1800 \\
\hline C12:1 & $-0.019(-0.045$ to 0.000$)$ & 0.0015 & $-0.030(-0.056$ to $(-0.009))$ & $<0.0001$ & 0.2160 \\
\hline C14 & -0.004 ( -0.011 to 0.003$)$ & $<0.0001$ & $-0.004(-0.013$ to 0.005$)$ & $<0.0001$ & 0.9039 \\
\hline C14:1 & $-0.018(-0.037$ to $(-0.005))$ & $<0.0001$ & $-0.024(-0.037$ to $(-0.004))$ & $<0.0001$ & 0.9379 \\
\hline $\mathrm{C} 14: 1-\mathrm{OH}$ & $-0.001(-0.007$ to 0.008$)$ & 0.8262 & $-0.002(-0.006$ to 0.004$)$ & 0.5096 & 0.5179 \\
\hline C14:2 & $-0.009(-0.018$ to $(-0.001))$ & $<0.0001$ & $-0.004(-0.015$ to 0.001$)$ & 0.0018 & 0.1529 \\
\hline $\mathrm{C} 14: 2-\mathrm{OH}$ & $0.001(-0.008$ to 0.007$)$ & 0.9380 & $0.000(-0.004$ to 0.007$)$ & 0.2544 & 0.9720 \\
\hline C16 & $-0.034(-0.053$ to $(-0.012)$ & $<0.0001$ & $-0.030(-0.048$ to $(-0.003))$ & $<0.0001$ & 0.3668 \\
\hline $\mathrm{C} 16-\mathrm{OH}$ & $-0.004(-0.009$ to 0.004$)$ & 0.3247 & $-0.002(-0.014$ to 0.005$)$ & 0.2893 & 0.7603 \\
\hline C16:1 & $-0.012(-0.023$ to 0.001$)$ & $<0.0001$ & $-0.009(-0.019$ to $(-0.002))$ & 0.0003 & 0.6482 \\
\hline $\mathrm{C} 16: 1-\mathrm{OH}$ & $-0.002(-0.010$ to 0.005$)$ & 0.0542 & $-0.004(-0.012$ to 0.004$)$ & 0.0718 & 0.8257 \\
\hline C16:2 & 0.000 (- 0.009 to 0.009$)$ & 0.3098 & $-0.001(-0.014$ to 0.010$)$ & 0.4121 & 0.9348 \\
\hline $\mathrm{C} 16: 2-\mathrm{OH}$ & $-0.002(-0.005$ to 0.003$)$ & 0.4349 & $-0.002(-0.006$ to 0.005$)$ & 0.8756 & 0.8915 \\
\hline C18 & $-0.029(-0.930$ to $(-0.010)$ & $<0.0001$ & $-0.032(-0.860$ to $(-0.010))$ & $<0.0001$ & 0.8032 \\
\hline C18:1 & $-0.054(-0.086$ to $(-0.020))$ & $<0.0001$ & $-0.052(-0.082$ to $(-0.026))$ & $<0.0001$ & 0.4525 \\
\hline $\mathrm{C} 18: 1-\mathrm{OH}$ & $-0.005(-0.014$ to 0.001$)$ & 0.0045 & $0.000(-0.009$ to 0.005$)$ & 0.9242 & 0.0980 \\
\hline C18:2 & $-0.017(-0.024$ to $(-0.004))$ & $<0.0001$ & $-0.016(-0.029$ to $(-0.007))$ & $<0.0001$ & 0.4541 \\
\hline
\end{tabular}

Data (with non-normal distribution) is shown as median change (interquartile range). Statistically significant $p$ values are in italics. $p$ values were calculated with Wilcoxon rank-sum test

Considering the results of the studies published about ACs, knowledge of the ACs profile may facilitate assessment of the patients' general metabolic milieu, mitochondrial functioning and prognosis.
ACs have a different origin in plasma. The main precursors of SCACs are branched chain amino acids (BCAAs) but some SCASs are also produced by catabolism of glucose and some triglycerides. MCACs and LCACS are 
Table 3 Substantial correlations between cardiac biomarkers (i.e. high sensitivity troponin $T$ and NT-proBNP) and acylcarnitines

\begin{tabular}{|c|c|c|c|c|c|c|c|c|}
\hline & \multicolumn{4}{|l|}{ Hs-TnT } & \multicolumn{4}{|l|}{ NT-proBNP } \\
\hline & $\operatorname{RIPC}(n=45)$ & $p$ value & SHAM $(n=47)$ & $p$ value & $\operatorname{RIPC}(n=45)$ & $p^{*}$ & SHAM $(n=47)$ & $p$ value \\
\hline C4 & 0.38 & 0.01 & -0.05 & 0.734 & 0.10 & 0.532 & -0.26 & 0.081 \\
\hline C5-DC & 0.18 & 0.230 & -0.29 & 0.050 & 0.15 & 0.320 & -0.16 & 0.276 \\
\hline $\mathrm{C} 5-\mathrm{OH}$ & 0.13 & 0.379 & -0.34 & 0.021 & -0.06 & 0.719 & 0.14 & 0.359 \\
\hline C7-DC & 0.07 & 0.639 & -0.08 & 0.580 & 0.18 & 0.241 & 0.28 & 0.055 \\
\hline $\mathrm{C} 10$ & 0.38 & 0.010 & -0.12 & 0.416 & 0.30 & 0.049 & -0.10 & 0.519 \\
\hline C10:1 & 0.38 & 0.010 & -0.12 & 0.404 & 0.18 & 0.225 & -0.12 & 0.405 \\
\hline C12:1 & 0.31 & 0.037 & -0.06 & 0.672 & 0.18 & 0.232 & -0.04 & 0.797 \\
\hline C16:1 & -0.15 & 0.341 & -0.25 & 0.090 & 0.10 & 0.500 & -0.35 & 0.016 \\
\hline C16:2 & 0.10 & 0.494 & -0.12 & 0.407 & 0.34 & 0.021 & 0.06 & 0.688 \\
\hline C18 & 0.05 & 0.745 & -0.11 & 0.476 & 0.17 & 0.268 & 0.31 & 0.031 \\
\hline C18:1 & 0.32 & 0.030 & -0.15 & 0.300 & 0.15 & 0.329 & -0.13 & 0.389 \\
\hline $\mathrm{C} 18-\mathrm{OH}$ & 0.35 & 0.019 & -0.07 & 0.628 & 0.12 & 0.431 & -0.27 & 0.07 \\
\hline
\end{tabular}

Statistically significant $p$ values and correlations are in italics

only derived from fatty acid metabolism whereas carnitine is required for transporting long-chain fatty acids into mitochondria [15]. SCASs in plasma has been found to be released from the liver [16], MCACs, from the skeletal muscles and liver [17] and LCACs, from the heart [15]. Taken together, the exact origin of plasma ACs is not clear, yet based on the assessment of whole ACs spectrum, conclusions can be drawn about the whole-body acylcarnitine metabolism. We observed an increase of some SCACs levels in the sham group whereas no any increase of ACs occurred in the RIPC group. It should be noted that the hepatoprotective effect of RIPC has been reported previously $[4,18]$.

Evidently, the stress caused by surgery enhances the catabolism of BCCA in the liver in order to produce additional metabolic energy and this is accompanied by an increase of plasma SCACs. RIPC has been found to intensify hepatic oxygenation and hepatic microcirculation via activation of eNOS [19], as well as to increase expression of protector proteins (e.g. heme oxygenase 1) [20], which preserves mitochondrial functionality. Hence, produced SCACs can be spent more efficiently in the case of RIPC and, based on our findings we could suppose that RIPC might have a protective effect on the liver. Surgery increases the demand for metabolic energy may also cause elevated level of ketone bodies leading to production of C3-OH. In RIPC, the elimination of this SCAC is more effective compared to the sham group, which results in a statistically significant difference between these groups.

As a response to any surgery, the human organism intensifies the production of metabolic energy, which is accompanied by additional spending of long chain fatty acids for energy-rich substrates through LCACs. This can explain for the decline in LCASs both in the sham and the RIPC group.

The cardioprotective effect of RIPC has been studied on humans since 2006 [21], however, results are contradictory. Although a previously published systematic review on patients undergoing non-cardiac vascular surgery reports no effect of RIPC in reducing myocardial injury [22], its cardioprotective effect has been described in more homogenous and more powerful studies with other populations. Cardioprotection by RIPC has been associated with the improved function of mitochondria [23-25]. However, two of these studies failed to demonstrate an effect of RIPC on cardioprotection and hence also correlation between cardioprotection and salvage of mitochondrial function [23, 24].

Previously, we have published a study on the same cohort, where we demonstrated positive effects of RIPC in reducing the levels of hsTnT and NT-proBNP [2]. In the present study, we describe positive correlations between decrease of these cardiac biomarkers and decrease of several ACs in the RIPC group. In the sham group, no positive correlations were noted between increase of hsTnT and increase of ACs. On the contrary, there was negative correlation between increase of hsTnT and increase of $\mathrm{C} 5-\mathrm{OH}$. Also there was a negative correlation between increase of NT-proBNP and C16:2 and positive correlation between increase of NT-proBNP and $\mathrm{C} 18$. The strength of correlations may have been weakened by inter-individual variations in the AC profiles coming from inter-individual differences in metabolism. Also, if our study had been larger, more definite conclusions about these correlations could be made. Although 
the changes of the above mentioned ACs between the groups were not significant, these differences between the sham and the RIPC group and the previously described cardioprotective effects of RIPC in the same cohort [2] suggest that the cardioprotective effects could be described basing on shifts in the levels of ACs.

However, further studies are needed to clarify these assumptions.

There are several limitations to our study. Firstly, the study population was heterogeneous as was also presumably their metabolic status. Although, there were no differences between study groups regarding comorbidities, health status, most common antihypertensive medications, treatment with statins and the baseline values of ACs, there might be a variation in response of ACs metabolism. It has been found that the levels of ACs differ among patients with different stages of PAD those without PAD [14]. As in our study there were patients with different locations and stages of atherosclerotic lesions, their metabolic status was evidently different, which may have influenced the results. Also we recruited both diabetic and non-diabetic patients in our groups and diabetes has been found to affect the levels of ACs [26] and have a deleterious effect on RIPC [27, 28].Moreover, the patients underwent different types of surgery and the extent of tissue damage was different. The patients undergoing open surgical repair of AAA probably experienced larger tissue damage and were not chronically preconditioned against ischaemia like might have been PAD patients who were undergoing lower limb revascularisation surgery. Thus the type of surgery may have had a great impact on the metabolism of ACs and the effect of RIPC may have been overwhelmed. In addition, in $42 \%$ of the patients in the RIPC group propofolinduced anaesthesia was used and propofol has been found to reduce the effect of RIPC [29]. Also, the size of the study group was relatively small and the true effect of RIPC might have been missed as there were multiple differences between the groups, which did not quite reach statistical significance.

\section{Conclusions}

It can be concluded that RIPC may have an effect on the levels of ACs and might therefore have protective effects on mitochondria in the vascular surgery patients. Further larger studies conducted on homogenous populations are needed to make more definite conclusions about the effect of RIPC on the metabolism of ACs.

\section{Supplementary information}

Supplementary information accompanies this paper at https://doi. org/10.1186/s12986-020-00495-3.
Additional file 1: Table S1. Baseline values of acylcarnitines. Table S2. Non-substantial correlations between cardiac biomarkers (i.e. high sensitivity troponin T and NT-proBNP) and acylcarnitines.

\section{Abbreviations}

AAA: Abdominal aortic aneurysm; ACs: Acylcarnitines; LCACs: Long chain acylcarnitines; MSCASs: Medium chain acylcarnitines; PAD: Peripheral artery disease; RIPC: Remote ischaemic preconditioning; SCASc: Short chain acylcarnitines.

\section{Acknowledgements}

The authors are indebted to Ms. E. Jaigma for the linguistic revision of the text.

\section{Author contributions}

TK, KK, UL, JS, MZ, JE and JK contributed to the design and implementation of the research, to the analysis of the results and to the writing of the manuscript. TK was the main contributor in writing the manuscript. JK conceived the original idea. MV performed the statistical analysis. All authors read and approved the final manuscript.

\section{Funding}

This study was supported by grants from the Estonian Research Council (PUT No. 1169, PUT PRG685, IUT No. 20-42, IUT No. 2-7, PRG435, PRG1054), and by the European Union through the European Regional Development Fund (Project No. 2014-2020.4.01.15-0012).

\section{Availability of data and materials}

The datasets used and/or analysed during the current study are available from the corresponding author on reasonable request.

\section{Ethics approval and consent to participate}

Signed informed consent was obtained from each patient. The research protocol of our study was approved by the Research Ethics Committee of the University of Tartu (Protocol's No. 252/M-24).

\section{Consent for publication}

Not applicable.

\section{Competing interests}

The authors declare that they have no competing interests.

\section{Author details}

${ }^{1}$ Department of Surgery, Institute of Clinical Medicine, University of Tartu, Puusepa 8, 50406 Tartu, Estonia. ${ }^{2}$ Department of Biochemistry, Institute of Biomedicine and Translational Medicine, Centre of Excellence for Genomics and Translational Medicine, University of Tartu, Tartu, Estonia. ${ }^{3}$ Department of Cardiology, Institute of Clinical Medicine, University of Tartu, Tartu, Estonia. ${ }^{4}$ Tartu University Hospital, Tartu, Estonia. ${ }^{5}$ Department of Anaesthesiology and Intensive Care, Institute of Clinical Medicine, University of Tartu, Tartu, Estonia. ${ }^{6}$ Institute of Mathematics and Statistics, University of Tartu, Tartu, Estonia.

Received: 15 April 2020 Accepted: 27 August 2020

Published online: 18 September 2020

\section{References}

1. Kasepalu T, Kuusik K, Lepner U, Starkopf J, Zilmer M, Eha J, et al. Remote ischaemic preconditioning reduces kidney injury biomarkers in patients undergoing open surgical lower limb revascularisation: a randomised trial. Oxid Med Cell Longev. 2020. https://doi.org/10.1155/2020/7098505.

2. Kepler T, Kuusik K, Lepner U, Starkopf J, Zilmer M, Eha J, et al. Remote ischaemic preconditioning attenuates cardiac biomarkers during vascular surgery: a randomised clinical trial. Eur J Vasc Endovasc Surg Off J Eur Soc Vasc Surg. 2020;59:301-8. https://doi.org/10.1016/j.ejvs.2019.09.502.

3. Zhang Y, Ma L, Ren C, Liu K, Tian X, Wu D, et al. Immediate remote ischemic postconditioning reduces cerebral damage in ischemic stroke 
mice by enhancing leptomeningeal collateral circulation. J Cell Physiol. 2019;234:12637-45. https://doi.org/10.1002/jcp.27858.

4. Wu G, Chen M, Wang X, Kong E, Yu W, Sun Y, et al. Effect of remote ischemic preconditioning on hepatic ischemia-reperfusion injury in patients undergoing liver resection: a randomized controlled trial. Minerva Anestesiol. 2019. https://doi.org/10.23736/S0375-9393.19.13838-2.

5. Pryds K, Bøttcher M, Sloth AD, Munk K, Rahbek Schmidt M, Bøtker HE. Influence of preinfarction angina and coronary collateral blood flow on the efficacy of remote ischaemic conditioning in patients with ST segment elevation myocardial infarction: post hoc subgroup analysis of a randomised controlled trial. BMJ Open. 2016. https://doi.org/10.1136/ bmjopen-2016-013314.

6. Gedik N, Maciel L, Schulte C, Skyschally A, Heusch G, Kleinbongard P. Cardiomyocyte mitochondria as targets of humoral factors released by remote ischemic preconditioning. Arch Med Sci AMS. 2017;13:448-58. https://doi.org/10.5114/aoms.2016.61789.

7. Paez DT, Garces M, Calabró V, Bin EP, D'Annunzio V, Del Mauro J, et al. Adenosine $\mathrm{A} 1$ receptors and mitochondria: targets of remote ischemic preconditioning. Am J Physiol Heart Circ Physiol. 2019;316:H743-50. https ://doi.org/10.1152/ajpheart.00071.2018.

8. Reuter SE, Evans AM. Carnitine and acylcarnitines: pharmacokinetic, pharmacological and clinical aspects. Clin Pharmacokinet. 2012;51:553-72. https://doi.org/10.1007/bf03261931.

9. Bjørndal B, Alterås EK, Lindquist C, Svardal A, Skorve J, Berge RK. Associations between fatty acid oxidation, hepatic mitochondrial function, and plasma acylcarnitine levels in mice. Nutr Metab. 2018. https://doi. org/10.1186/s12986-018-0241-7.

10. Wishart DS, Feunang YD, Marcu A, Guo AC, Liang K, Vázquez-Fresno R, et al. HMDB 4.0: the human metabolome database for 2018. Nucl Acids Res. 2018;46:D608-17. https://doi.org/10.1093/nar/gkx1089.

11. McGill MR, Li F, Sharpe MR, Williams CD, Curry SC, Ma X, et al. Circulating acylcarnitines as biomarkers of mitochondrial dysfunction after acetaminophen overdose in mice and humans. Arch Toxicol. 2014;88:391-401. https://doi.org/10.1007/s00204-013-1118-1.

12. Kepler T, Kuusik K, Lepner U, Starkopf J, Zilmer M, Eha J, et al. The effect of remote ischaemic preconditioning on arterial stiffness in patients undergoing vascular surgery: a randomised clinical trial. Eur J Vasc Endovasc Surg. 2019;57:868-75. https://doi.org/10.1016/j.ejvs.2018.12.002.

13. Xia F-Y, Zhu L, Xu C, Wu Q-Q, Chen W-J, Zeng R, et al. Plasma acylcarnitines could predict prognosis and evaluate treatment of IgA nephropathy. Nutr Metab. 2019;16:2. https://doi.org/10.1186/s12986-018-0328-1.

14. Ismaeel A, Franco ME, Lavado R, Papoutsi E, Casale GP, Fuglestad M, et al. Altered metabolomic profile in patients with peripheral artery disease. J Clin Med. 2019. https://doi.org/10.3390/jcm8091463.

15. Makrecka-Kuka M, Sevostjanovs E, Vilks K, Volska K, Antone U, Kuka J, et al. Plasma acylcarnitine concentrations reflect the acylcarnitine profile in cardiac tissues. Sci Rep. 2017;7:1-11. https://doi.org/10.1038/s41598-01717797-x.

16. Schooneman MG, Ten Have GAM, van Vlies N, Houten SM, Deutz NEP, Soeters MR. Transorgan fluxes in a porcine model reveal a central role for liver in acylcarnitine metabolism. Am J Physiol Endocrinol Metab. 2015;309:E256-64. https://doi.org/10.1152/ajpendo.00503.2014.

17. Xu G, Hansen JS, Zhao XJ, Chen S, Hoene M, Wang XL, et al. Liver and muscle contribute differently to the plasma acylcarnitine pool during fasting and exercise in humans. J Clin Endocrinol Metab. 2016;101:504452. https://doi.org/10.1210/jc.2016-1859.
18. Kanoria S, Robertson FP, Mehta NN, Fusai G, Sharma D, Davidson BR. Effect of remote ischaemic preconditioning on liver injury in patients undergoing major hepatectomy for colorectal liver metastasis: a pilot randomised controlled feasibility trial. World J Surg. 2017;41:1322-30. https://doi.org/10.1007/s00268-016-3823-4.

19. Abu-Amara M, Yang SY, Quaglia A, Rowley P, Fuller B, Seifalian A, et al. Role of endothelial nitric oxide synthase in remote ischemic preconditioning of the mouse liver. Liver Transpl Off Publ Am Assoc Study Liver Dis Int Liver Transpl Soc. 2011;17:610-9. https://doi.org/10.1002/lt.22272.

20. Cornide-Petronio ME, Jiménez-Castro MB, Gracia-Sancho J, Peralta C. Ischemic preconditioning directly or remotely applied on the liver to reduce ischemia-reperfusion injury in resections and transplantation. Liv Dis Surg. 2019. https://doi.org/10.5772/intechopen.86148.

21. Cheung MMH, Kharbanda RK, Konstantinov IE, Shimizu M, Frndova H, $\mathrm{Li}$ J, et al. Randomized controlled trial of the effects of remote ischemic preconditioning on children undergoing cardiac surgery: first clinical application in humans. J Am Coll Cardiol. 2006;47:2277-82. https://doi. org/10.1016/j.jacc.2006.01.066.

22. Stather PW, Wych J, Boyle JR. A systematic review and meta-analysis of remote ischemic preconditioning for vascular surgery. J Vasc Surg. 2019;70:1353-1363 e3. https://doi.org/10.1016/j.jvs.2019.03.025.

23. Ferko M, Kancirová I, Jašová M, Čarnická S, Muráriková M, Waczulíková I, et al. Remote ischemic preconditioning of the heart: protective responses in functional and biophysical properties of cardiac mitochondria. Physiol Res. 2014;63(Suppl 4):S469-478.

24. Slagsvold KH, Moreira JBN, Rognmo Ø, Høydal M, Bye A, Wisløff U, et al. Remote ischemic preconditioning preserves mitochondrial function and activates pro-survival protein kinase Akt in the left ventricle during cardiac surgery: a randomized trial. Int J Cardiol. 2014;177:409-17. https:// doi.org/10.1016/j.jijcard.2014.09.206.

25. Petra K, Nilguen G, Mücella K, Leanda S, Ulrich F, Afsaneh Z, et al. Mitochondrial and contractile function of human right atrial tissue in response to remote ischemic conditioning. J Am Heart Assoc. 2018;7:e009540. https://doi.org/10.1161/JAHA.118.009540.

26. Schooneman MG, Vaz FM, Houten SM, Soeters MR. Acylcarnitines: reflecting or inflicting insulin resistance? Diabetes. 2013;62:1-8. https://doi. org/10.2337/db12-0466.

27. Moretti C, Cerrato E, Cavallero E, Lin S, Rossi ML, Picchi A, et al. The EUROpean and Chinese cardiac and renal Remote Ischemic Preconditioning Study (EURO-CRIPS CardioGroup I): a randomized controlled trial. Int J Cardiol. 2018;257:1-6. https://doi.org/10.1016/j.ijcard.2017.12.033.

28. Wider J, Undyala W, Whittaker P, Przyklenk K. Abstract 19195: remote ischemic preconditioning fails to reduce infarct size in type-2 diabetes: role of defective humoral communication. Circulation. 2017;136:A19195A19195. https://doi.org/10.1161/circ.136.suppl_1.19195.

29. Behmenburg F, van Caster P, Bunte S, Brandenburger T, Heinen A, HolImann $\mathrm{MW}$, et al. Impact of anesthetic regimen on remote ischemic preconditioning in the rat heart in vivo. Anesth Analg. 2018;126:1377-80. https://doi.org/10.1213/ANE.0000000000002563.

\section{Publisher's Note}

Springer Nature remains neutral with regard to jurisdictional claims in published maps and institutional affiliations

$$
\begin{aligned}
& \text { Ready to submit your research? Choose BMC and benefit from: } \\
& \text { - fast, convenient online submission } \\
& \text { - thorough peer review by experienced researchers in your field } \\
& \text { - rapid publication on acceptance } \\
& \text { - support for research data, including large and complex data types } \\
& \text { - gold Open Access which fosters wider collaboration and increased citations } \\
& \text { - maximum visibility for your research: over } 100 \mathrm{M} \text { website views per year }
\end{aligned}
$$

At BMC, research is always in progress.

Learn more biomedcentral.com/submissions 